\title{
AS USINAS CANAVIEIRAS NA MESORREGIÃO DE ARAÇATUBA: ANÁLISE DOS INDICADORES SOCIOECONÔMICOS NOS MUNICÍPIOS
}

\author{
Ércio Roberto Proença ${ }^{1 *}$, Maria Aparecida Anselmo Tarsitano ${ }^{1}$, Rosalina Maria Alves \\ Rapassi $^{2}$, Rodrigo Anselmo Tarsitano ${ }^{3}$, Silvia Maria Almeida Lima Costa ${ }^{1}$
}

\footnotetext{
${ }^{1}$ Docente do Departamento de Fitotecnia, Tecnologia de Alimentos e Sócio Economia na UNESP - Campus de Ilha Solteira (SP). *E-mail: proenca@agr.feis.unesp.br

${ }^{2}$ Pós-doutoranda na UNESP - Campus de Ilha Solteira (SP).

${ }^{3}$ Docente na UNEMAT - Campus Universitário de Nova Xavantina (MT).
}

RESUMO: Este artigo analisa os impactos socioeconômicos nos municípios da mesorregião de Araçatuba gerados com a implantação das usinas canavieiras. Utilizou-se dados secundários, do Instituto Brasileiro de Geografia e Estatística - IBGE, da FSEADE, do Ministério do Trabalho e Emprego - MTE, da Federação das Indústrias do Estado do Rio de Janeiro - FIRJAN e IPEADATA. Os resultados mostraram que no período 2000-2010 com a presença de usinas canavieiras, houve um crescimento da população urbana, além da perda da população rural. Além disso, a instalação das usinas estimulou o crescimento do número de empregos formais em todos os setores (indústria, comércio e serviços) no cômputo total da mesorregião, exceção feita ao setor agropecuário que reduziu. Por fim, os resultados apresentados mostraram uma melhoria no índice da Firjan de 2000 a 2009 para os municípios com presença de usinas.Entretanto em todo o período, não tenha havido mudança de estágio, continuam classificados como desenvolvimento moderado.

\section{Palavras-chave: Impactos socioeconômicos. Usinas canavieiras. Mesorregião de Araçatuba. \\ THE SUGARCANE PLANTS IN THE MESOREGION OF ARAÇATUBA: ANALYSIS OF THE SOCIOECONOMICS INDICATORS IN THE MUNICIPALITIES}

\begin{abstract}
This article analyzes the socioeconomic impacts of the municipalities mesoregion Araçatuba generated with the deployment of sugarcane plants. We used secondary data from the Brazilian Institute of Geography and Statistics - IBGE, of FSEADE, the Ministry of Labor and Employment-MTE, the Federation of Industries of the State of Rio de Janeiro and FIRJAN IPEADATA. The results showed that in the 2000-2010 period with the presence of sugarcane plants, there was a growing urban population, and the loss of rural population. Furthermore, the installation of plants stimulated growth in the number of formal jobs in all sectors (industry, trade and services) in total mesoregion computation, except for the agricultural sector has reduced. Finally, the results showed an improvement in the index of Firjan from 2000 to 2009 for municipalities with presence of plants. Although the whole period, there has been a change in stage, remain classified as moderate development.
\end{abstract}

Cultura Agronômica, Ilha Solteira, v.24, n.2, p.181-196, 2015 
Key words: Socioeconomic impacts. Sugarcane mills. Mesoregion Araçatuba.

\section{INTRODUÇÃO}

A produção mundial de cana-de-açúcar em 2011, em uma área de 25,4 milhões de hectares, foi de 1.794,3 milhões de toneladas. O Brasil é o maior produtor de cana-de-açúcar com quase $41 \%$ da produção mundial, seguido por Índia (19\%) e China $(6,4 \%)$. O país também é o maior exportador de açúcar e álcool a partir da cana-de-açúcar (AGRIANUAL, 2014).

A produção total de cana-de-açúcar moída na safra 2014/15, divulgada pela Companhia Nacional de Abastecimento - CONAB (2014), é estimada em 671,69milhões de toneladas, representando um aumento de 2,0\% em relação à safra 2013/14, que foi de 658,82 milhões de toneladas. A área cultivada será de 9.130,10 mil hectares, acréscimo de 3,6\% relação a safra anterior. São Paulo, Mato Grosso do Sul, Goiás e Paraná foram os estados com maior acréscimo de áreas, com 144,3 mil hectares, 57,9 mil hectares, 59,9 mil hectares e 58,3 mil hectares, respectivamente. Este crescimento ocorreu, principalmente, devido à expansão de novas áreas de plantio e de novas usinas em funcionamento.

A produção de etanol total para a safra 2014/15 está estimada em 28,37 bilhões de litros ano,um incremento de 1,47\% em relação aos 27,96 bilhões de litros da safra 2013. Já a produção de açúcar para esta safra 2014/15 está estimada em 39,46 milhões de toneladas, $4,17 \%$ a mais que a safra passada. Cerca de $71,48 \%$ do açúcar no país foi produzido na Região Sudeste, $10,87 \%$ na Região Centro-Oeste, $8,90 \%$ na Região Nordeste, 8,64\% na Região Sul e $0,12 \%$ na Região Norte.O percentual de açúcar total recuperável (ATR) destinado à produção de açúcar nesta safra está estimado em 46,09\% do total (CONAB, 2014).

As unidades agroindustriais produtoras de açúcar e álcool cadastradas no Departamento da cana-de-açúcar e agroenergia totalizavam 390 unidades, deste total, 204 unidades são mistas, isto é, produzem açúcar e álcool, 122 somente álcool, 15 unidades produzem açúcar e 49 não informaram (sem lançamento) no Brasil. No Estado de São Paulo são 168 unidades produtoras de açúcar e álcool, com 93 usinas mistas, 33 produtoras de etanol, 5 produtoras de açúcar e 37 não informaram (sem lançamento) (BRASIL, 2014).

Nos últimos anos vem ocorrendo expansão da produção de cana-de-açúcar no Estado de São Paulo decorrente das condições favoráveis em relação ao mercado internacional de açúcar e álcool e no mercado nacional pela demanda de carros flex (CAMARGO JÚNIOR; TONETO JÚNIOR, 2009). Dados mais recentes do Ministério do Desenvolvimento, Indústria e Comércio Exterior (MDIC) mostraram uma queda nas exportações a partir de 2008 de 5,1 bilhões de litros para 2,0 bilhões em 2011, em 2012 se recupera com 3,1 bilhões e em 2013 o valor foi de 2,9 bilhões de litros. Em 2013, o mercado internacional de biocombustíveis manteve a gradual diminuição dos incentivos para estes produtos e os volumes transacionados permaneceram modestos (BRASIL, 2014).

Cultura Agronômica, Ilha Solteira, v.24, n.2, p.181-196, 2015 
No Estado de São Paulo, a região oeste, vem se destacando no crescimento da área --cultivada com cana-de-açúcar. De acordo com dados divulgados pelo Instituto Nacional de Pesquisas Espaciais, a área cultivada com cana disponível para colheita, no período de 2003 a 2011, apresentou um aumento de $155 \%$, enquanto que no estado de São Paulo a variação foi menor de $80 \%$ (PROENÇA, 2012).

Alguns estudos, como Montagnhani et al. (2009) e Shikida e Souza (2009) analisaram o impacto da instalação de usinas de açúcar e álcool no desenvolvimento local. O primeiro estudo concluiu que houve crescimento econômico e melhoria no desenvolvimento do município de Mirandópolis entre 1991-2000, pois ocorreu crescimento da renda per capita e redução da desigualdade mensurada pelo índice de Gini. No segundo estudo, a instalação da Usina Usaciga no município de Cidade Gaúcha (PR) desencadeou elevação das receitas do município.

Neste contexto, este trabalho, analisa a expansão do setor canavieiro e seus reflexos nos municípios localizados na mesorregião de Araçatuba, localizada a oeste de São Paulo. Especificamente, se existem mudanças em alguns indicadores sociais e econômicos nos municípios após a implantação das mesmas.

\section{MATERIAL E MÉTODOS}

A abrangência do estudo teve como referência a Mesorregião Geográfica de Araçatuba, uma das quinze mesorregiões do Estado de São Paulo, formada pela união de 36 municípios agrupados em três microrregiões:

- Andradina: Andradina, Castilho, Guaraçaí, Ilha Solteira, Itapura, Mirandópolis, Murutinga do Sul, Nova Independência, Pereira Barreto, Sud Mennucci e Suzanápolis;

- Araçatuba:Araçatuba, Bento de Abreu, Guararapes, Lavínia, Rubiácea, Santo Antônio do Aracanguá e Valparaíso, e

- Birigui: Alto Alegre, Avanhandava, Barbosa, Bilac, Birigui, Braúna, Brejo Alegre, Buritama, Clementina, Coroados, Gabriel Monteiro, Glicério, Lourdes, Luiziânia, Penápolis, Piacatu, Santópolis do Aguapeí e Turiúba.

Na Figura 1, visualiza-se o Estado de São Paulo dividido em 64 microrregiões, destacando as três que fazem parte deste estudo.

Cultura Agronômica, Ilha Solteira, v.24, n.2, p.181-196, 2015 


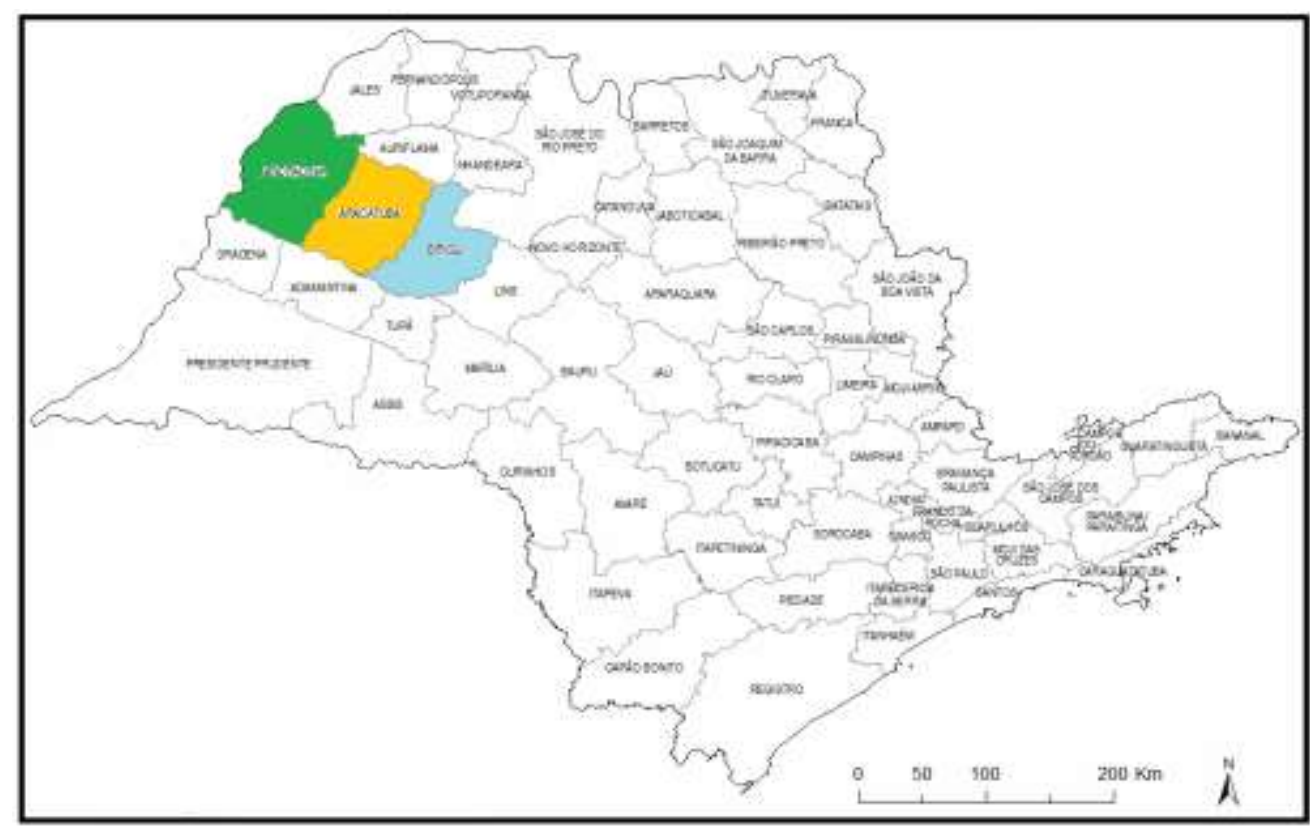

Figura 1. O Estado de São Paulo dividido em 64 Microrregiões, destacando as microrregiões estudadas.

Fonte: IBGE (2012).

Para estudar os impactos socioeconômicos na mesorregião de Araçatuba, foram levantados e analisados os seguintes indicadores:

- População residente urbana e rural: as categorias rural e urbana de uma unidade geográfica são, no Brasil, definidas por lei municipal. Os critérios para determinar se um domicílio fica na zona rural ou urbana são políticos e variam, portanto, de um município a outro; em relação aos domicílios, o IBGE, órgão responsável pelo Censo Demográfico, identifica duas situações: a) em "situação urbana" estão os domicílios que se localizam em áreas urbanizadas ou não, correspondentes às Cidades (Sedes Municipais), às Vilas (Sedes Distritais) ou às Áreas urbanas Isoladas; b) em "situação rural" estão os domicílios que se localizam fora dos limites acima definidos, inclusive os Aglomerados Rurais de Extensão Urbana, os Povoados e os Núcleos. Neste trabalho esses dados foram levantados no Instituto Brasileiro de Geografia e Estatística - IBGE e na FSEADE (2012);

- Vínculo empregatício por setor de atividade econômica: o número de empregos formais corresponde aos vínculos empregatícios ativos em 31 de dezembro de cada ano, de acordo com as informações fornecidas pelos contratantes quando da elaboração da Relação Anual de Informações Sociais - RAIS, do Ministério do Trabalho e Emprego - MTE. Entende-se como vínculo empregatício a relação de emprego mantida com o empregador durante o ano-base e que se estabelece sempre que ocorrer trabalho remunerado com submissão hierárquica ao empregador e horário preestabelecido por este. Esta relação pode ser regida pela Consolidação das Leis do Trabalho - CLT ou pelo Regime Jurídico Único, no caso de empregado estatutário do serviço público. Os dados foram obtidos na FSEADE (2012), a partir de dados primários publicados na FIBGE; 
- Produto Interno Bruto per capita (PIB per capita): refere-se ao valor agregado de todos os bens e serviços finais produzidos dentro do território do país, independente da nacionalidade dos proprietários das unidades produtoras desses bens e serviços. $\mathrm{O}$ PIB per capita é obtido dividindo o valor do PIB pela população da respectiva agregação geográfica, neste caso, pela população de cada município participante da pesquisa (17 com usinas e 19 sem usinas) e pelo total da mesorregião de Araçatuba. Neste trabalho os dados foram obtidos na FSEADE (2012) a partir de dados do FIBGE; e

- Índices da Federação das Indústrias do Estado do Rio de Janeiro - FIRJAN de Desenvolvimento Municipal (IFDM): é um estudo anual do Sistema FIRJAN que acompanha o desenvolvimento de todos os 5.564 municípios brasileiros. É realizado exclusivamente, com base em estatísticas públicas oficiais, disponibilizadas pelos ministérios do Trabalho, Educação e Saúde. Os dados foram levantados e analisados nos anos 2000, 2005 e 2009 do IPEADATA (BRASIL, 2012). O índice considera, com igual ponderação, as três principais áreas de desenvolvimento humano: Emprego e Renda, Educação e Saúde. São considerados para cada área de desenvolvimento humano os seguintes indicadores:Emprego e renda: geração de emprego formal, estoque de emprego formal, salários médios do emprego formal;Educação: taxa de matrícula na educação infantil, taxa de abandono, taxa de distorção, idade-série, percentual de docentes com ensino superior, média de horas aula diárias, resultado do Índice de Desenvolvimento da Educação Básica (IDEB) ${ }^{1}$., e Saúde: número de consultas pré-natal, óbitos por causas mal definidas, óbitos infantis por causas evitáveis.

O índice varia entre 0 e 1 (quanto mais próximo de 1 , maior será o nível de desenvolvimento da localidade). Com base nessa metodologia, estipularam-se as seguintes classificações:

a. municípios com IFDM entre 0 e 0,4

baixo estágio de desenvolvimento;

b. municípios com IFDM entre 0,4 e 0,6 desenvolvimento regular;

c. municípios com IFDM entre 0,6 e 0,8 desenvolvimento moderado;

d. municípios com IFDM entre 0,8 e 1,0 alto estágio de desenvolvimento.

\section{RESULTADOS E DISCUSSÃO}

A evolução da população urbana e rural residentes nos municípios que implantaram usinas canavieiras e dos que não possuem usinas nos anos de 2000 e 2010 está discriminada na Tabela 1.

Considerando o período de 2000 a 2010, houve uma queda da população rural de $13,1 \%$, ou seja, -4.609 pessoas nos municípios onde foram implantadas usinas e um aumento $12,2 \%$ onde não havia usinas canavieiras. Com relação à população urbana

\footnotetext{
${ }^{1}$ Com o Ideb, ampliam-se as possibilidades de mobilização da sociedade em favor da educação, uma vez que o índice é comparável nacionalmente e expressa em valores os resultados mais importantes da educação: aprendizagem e fluxo.
}

Cultura Agronômica, Ilha Solteira, v.24, n.2, p.181-196, 2015 
constatou-se um crescimento de 9,5\% para populações com usinas e 13,1 \% nas populações dos municípios sem Usinas. Esses resultados podem ser melhor visualizados na Figura 2. Isso pode ser explicado, pelo menos em parte, pelo movimento de mudança nos domicílios do pequeno e médio produtor rural, quando do contrato de arrendamento da terra, em geral passam a fixar residência na área urbana.

Tabela 1. População urbana e rural dos municípios com e sem usinas canavieiras na mesorregião de Araçatuba.

\begin{tabular}{llcr}
\hline \multirow{2}{*}{ Municípios } & Residência & $\mathbf{2 0 0 0}$ & Anos \\
\cline { 3 - 4 } Com usinas & Urbana & 408.901 & $\mathbf{2 0 1 0}$ \\
\hline (17 municípios) & Rural & 35.068 & 447.826 \\
& & & 30.459 \\
Sem usinas & Urbana & 171.937 & 194.431 \\
$(19$ municípios) & Rural & 19.314 & 21.678 \\
\hline
\end{tabular}

Fonte: Elaborada pelo autor a partir de dados da FSEADE (2012).

2000-2010

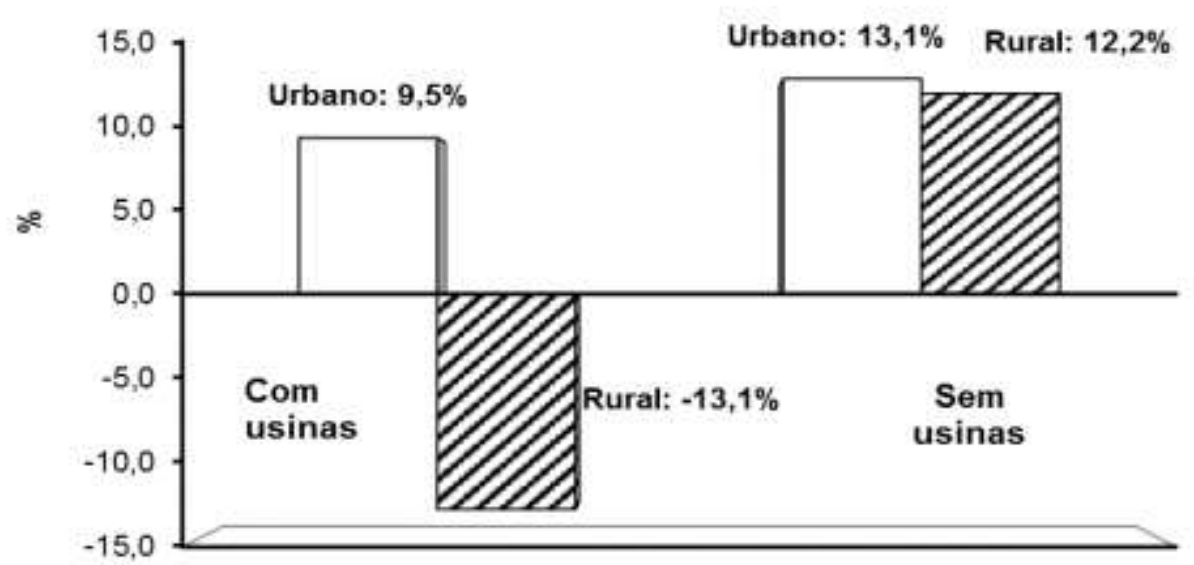

Figura 2. Variação percentual da população dos municípios com e sem usinas canavieiras da mesorregião de Araçatuba 2000-2010.

Fonte: Elaborado pelo autor a partir de dados da FSEADE (2012).

$\mathrm{Na}$ tabela 2, verifica-se que o vínculo empregatício, isto é, o número de pessoas ocupadas no setor industrial, no período de 2000 a 2010 cresceu em todos os municípios com usinas canavieiras na mesorregião de Araçatuba, exceção feita ao município de Guararapes que apresentou uma redução de 14,8\%. Apesar de Nova Independência ter apresentado maior taxa de crescimento de quase $14.000 \%$ verifica-se que até 2005 o número de empregos era baixo, de 71 aumentou para 833 em 2010. A presença da Usina Ipê pode ser responsável por esse aumento após a instalação em 2008. Segundo informações da pesquisa, o município de Nova Independência é cercado por duas usinas: a Usina Ipê do 


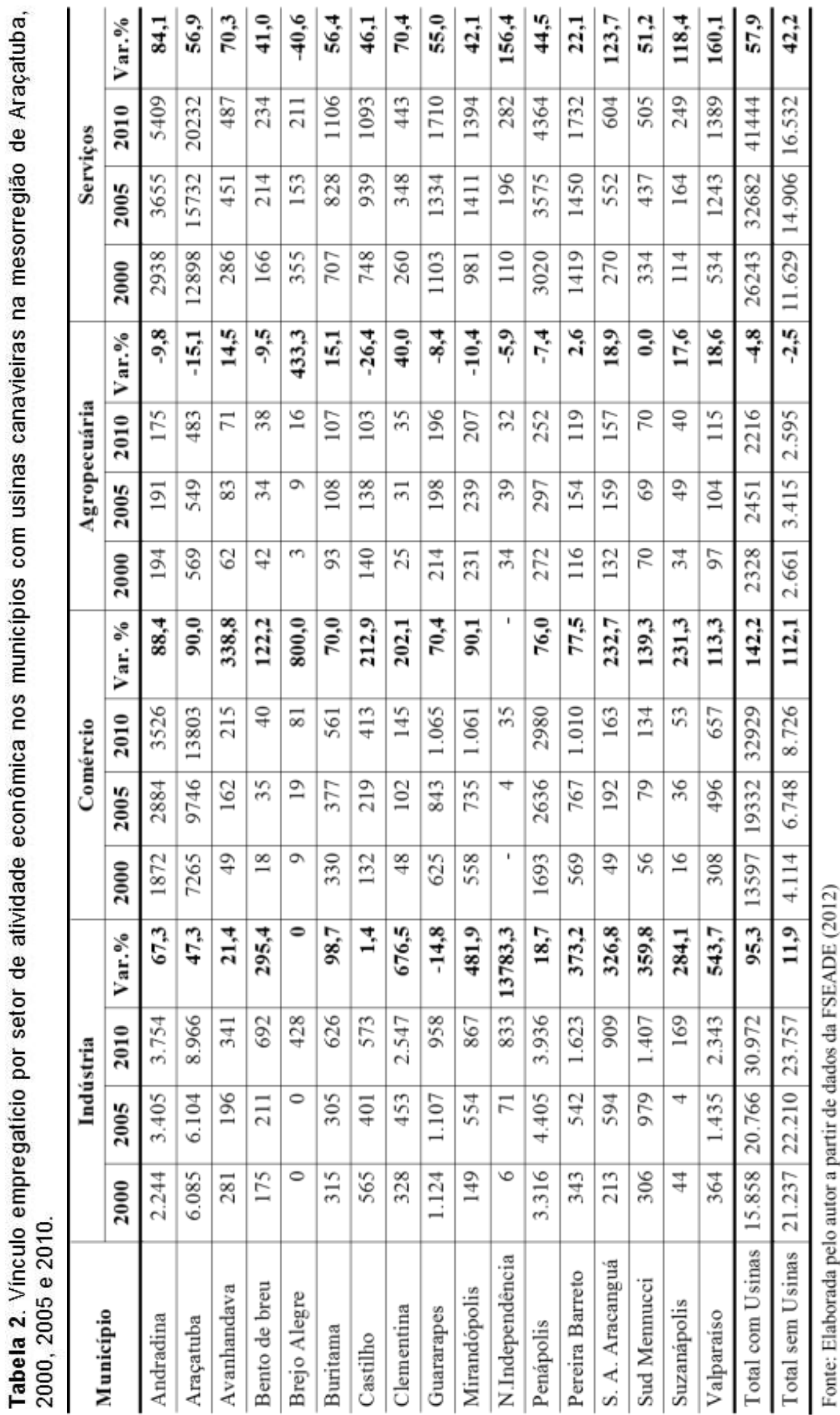

Cultura Agronômica, Ilha Solteira, v.24, n.2, p.181-196, 2015 
Grupo Pedra Agroindustrial S/A situada no município e, a Usina Virálcool do Grupo da mesma denominação situada em Castilho, sendo que parte da população do município trabalha na Virálcool trazendo para o município o efeito transferência de renda.

O setor comércio revela que houve crescimento em todos os municípios para o período. No setor agropecuário dos 17 municípios com usinas, 8 apresentam redução variando entre 5,9\% (Nova Independência) e 26,4\% (Castilho). Já no setor de serviços apenas o município de Brejo Alegre apresentou redução (40,6\%), os outros municípios apresentaram variação positiva, Araçatuba como é o maior município apresentou maior número devínculo empregatício em 2010 (20.232). Em termos percentuais a menor variação foi $22,1 \%$ (Pereira Barreto) e a maior $160,1 \%$ (Valparaíso).

Quando comparado o total dos vínculos empregatícios dos municípios com e sem usinas canavieiras houve uma expansãono setor industrial de 95,3\% (com) e 11,9\% (sem); $142,2 \%$ (com) e $112,1 \%$ (sem) no setor de comércio; $-4,8 \%$ (com) e -2,5\% (sem) no setor agropecuário e, no setor de serviços 57,9 (com) e 42,2\% (sem) usinas canavieiras (Figura 3).

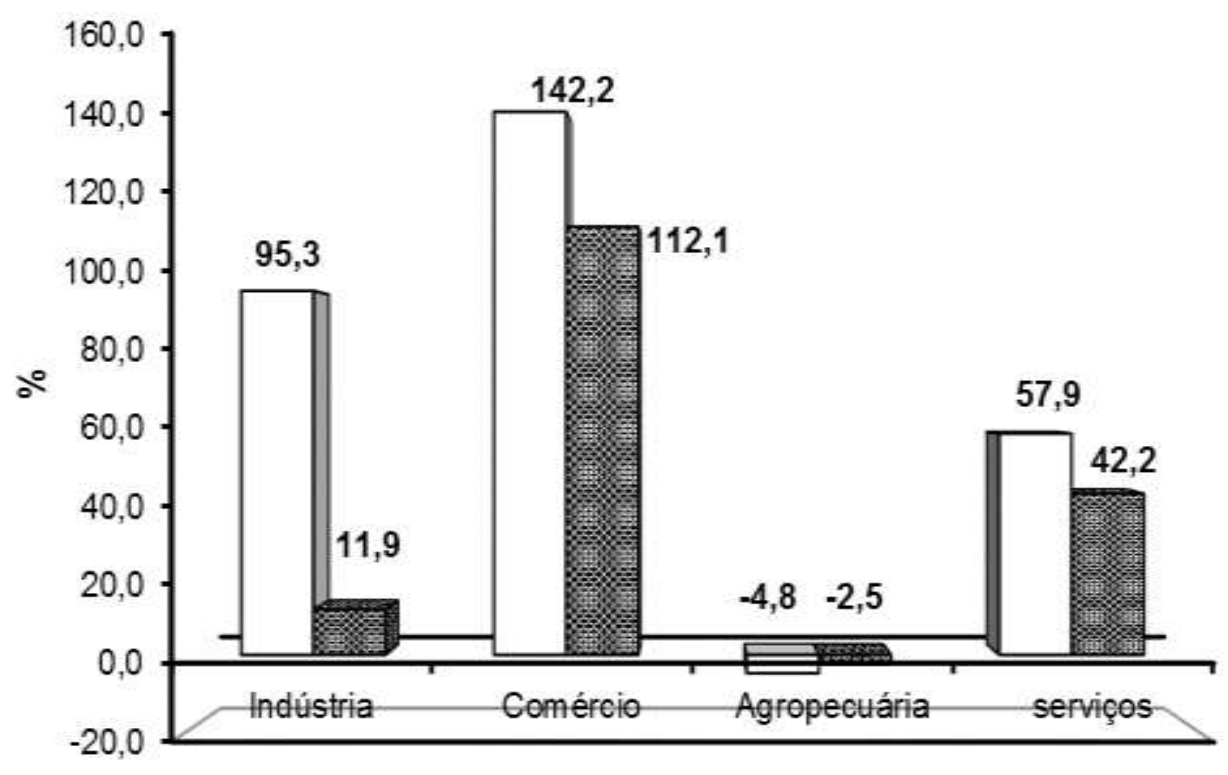

口Com usinas $\quad$ rSem usinas

Figura 3. Variação Percentual do vínculo empregatício por setor de atividade econômica nos municípios com e sem usinas canavieiras na mesorregião de Araçatuba, 2000-2010. Fonte: Elaborada pelo autor a partir de dados da FSEADE (2012).

O que deve ser destacado é que nos municípios com usinas esse crescimento foi de mais de 15.000 novos empregos no setor industrial, ou seja, passando de 15.858 para 30.972, no período entre 2000 a 2010. Enquanto, que no total dos municípios sem usinas apresentou um crescimento considerável, porém com menor destaque em relação aos municípios com usinas passando de 21.237 para 23.757, gerando 2.520 empregos.

Com relação ao setor de comércio, do total dos municípios com usinas foi o setor que apresentou maior geração de novos postos de trabalho, produzindo 19.332 empregos para a Cultura Agronômica, Ilha Solteira, v.24, n.2, p.181-196, 2015 
economia da mesorregião, ao passo que nos municípios sem usinas o crescimento foi mais tímido, criação de 4.612 novos empregos. Outro setor que mostrou dinamismo no que tange a produção de novos empregos foi o setor de serviços com 15.201 nos municípios com usinas e 4.903 nos municípios sem usinas

Em contrapartida o setor agropecuário apresentou redução no nível de empregos tanto nos municípios com usinas com menos 112 vínculos empregatícios como nos municípios sem usinas com subtração de 66 empregos. Cabe ressaltar que no mesmo período de análise observa-se que havia uma perda da população rural no mesmo período estudado de $13,1 \%$. Este fato se deve em parte ao inverso que aconteceu com a população urbana com crescimento de $9,5 \%$. Por outro lado nos municípios sem as usinas houve crescimento em ambos os municípios, com usinas $(13,1 \%)$ e sem usinas $(12,2 \%)$.

Tabela 3. Produto Interno Bruto*per capita a preços constantes em Reais dos municípios com usinas, e do total com e sem usinas e da mesorregião de Araçatuba, 2000, 2005 e 2009.

\begin{tabular}{l|r|r|r|r}
\hline Município & \multicolumn{1}{|c|}{$\mathbf{2 0 0 0}$} & \multicolumn{1}{|c|}{$\mathbf{2 0 0 5}$} & \multicolumn{1}{|c|}{$\mathbf{2 0 0 9}$} & Var. \% 00/09 \\
\hline Andradina & $15.812,21$ & $12.124,45$ & $16.777,47$ & 6,1 \\
Araçatuba & $15.213,06$ & $12.633,23$ & $16.472,19$ & 8,3 \\
Avanhandava & $9.820,54$ & $9.771,93$ & $9.838,74$ & 0,2 \\
Bento de Abreu & $23.749,56$ & $28.337,19$ & $21.859,80$ & $-8,0$ \\
Brejo Alegre & $12.023,27$ & $9.893,54$ & $38.446,07$ & 219,8 \\
Buritama & $16.419,49$ & $13.427,73$ & $14.747,81$ & $-10,2$ \\
Castilho & $54.629,07$ & $41.005,11$ & $39.684,12$ & $-27,4$ \\
Clementina & $9.383,04$ & $10.477,01$ & $9.332,26$ & $-0,5$ \\
Guararapes & $17.125,31$ & $18.601,43$ & $17.949,97$ & 4,8 \\
Mirandópolis & $9.636,24$ & $7.885,91$ & $9.078,94$ & $-5,8$ \\
Nova Independência & $11.572,03$ & $13.875,71$ & $76.752,55$ & 563,3 \\
Penápolis & $12.653,39$ & $14.780,95$ & $14.946,02$ & 18,1 \\
Pereira Barreto & $16.932,57$ & $13.804,48$ & $27.611,89$ & 63,1 \\
Santo Antônio do Aracanguá & $20.857,99$ & $27.353,35$ & $26.158,72$ & 25,4 \\
Sud Mennucci & $10.431,48$ & $13.596,52$ & $15.940,46$ & 52,8 \\
Suzanápolis & $12.384,19$ & $15.766,57$ & $28.010,89$ & 126,2 \\
Valparaíso & $11.972,34$ & $13.447,15$ & $14.525,36$ & 21,3 \\
\hline Total com usinas & $\mathbf{2 8 0 . 6 1 5 , 8 1}$ & $\mathbf{2 7 6 . 7 8 2 , 2 6}$ & $\mathbf{3 9 8 . 1 3 3 , 2 6}$ & $\mathbf{4 1 , 9}$ \\
\hline Total sem usinas & $\mathbf{2 4 6 . 0 6 8 , 1 0}$ & $\mathbf{1 2 6 . 7 3 4 , 5 4}$ & $\mathbf{2 6 4 . 4 7 5 , 9 0}$ & $\mathbf{7 , 4 8}$ \\
\hline Total da mesorregião & $\mathbf{5 2 6 . 6 8 3 , 9 0}$ & $\mathbf{4 0 3 . 5 1 6 , 8 0}$ & $\mathbf{6 6 2 . 6 0 9 , 1 6}$ & $\mathbf{2 5 , 8}$ \\
\hline Defla
\end{tabular}

*Deflacionado pelo IGP-DI/FGV.

Fonte: Elaborada pelo autor a partir de dados da FSEADE (2012).

É evidente que o complexo agroindustrial nos municípios com usinas canavieiras não foram únicas responsáveis pelo aumento do emprego, mas sem dúvida tiveram uma participação relevante nessa ampliação. Em estudo realizado por Barbosa et al. (2011), os resultados apresentaram uma expressiva receptividade à implantação da usinaem Minas Gerais, principalmente pela importância econômica do setor, devido à geração de empregos e aumento da renda, mesmo que beneficiando pequena parcela da população. Entretanto, Cultura Agronômica, Ilha Solteira, v.24, n.2, p.181-196, 2015 
existe uma preocupação com aspectos ambientais como, por exemplo, a poluição e problemas sociais devido à migração de pessoas de outras regiões do país, além do aumento do custo de vida.

A Tabela 3 apresenta o Produto Interno Bruto (PIB) per capita de todos os municípios da mesorregião de Araçatuba que têm a presença de usinas canavieiras. O PIB per capita é medido pela renda devida à produção dentro dos limites territoriais do país dividida pela população a preços nominais, isto é, incorpora além da variação de volume a variação de preçosnos anos de 2000, 2005 e 2009. Neste caso os preços foram deflacionados pelo IGP$\mathrm{DI}^{2}$

Observa-se que dos 17 municípios com presença de usinas, 12 registraram crescimento. Nova Independência apresentou maiorvariação de 563,3 \%, de R \$ 11.572,03 em 2000 para R\$76.752,55 em 2009. Na decomposição do PIB, observa-se que os fatores que contribuíram para esse aumento foram o setor industrial com variação de $846 \%$, e a arrecadação dos impostos com 402\%, para o mesmo período (BRASIL, 2012).

Por outro lado, 5 municípios exibiram taxas negativas, o município de Castilho em 2000 contava com o PIB per capita real era de $\mathrm{R} \$ 54.629,07$ (o valor nominal $\mathrm{R} \$$ $26.600,16$ ) e em 2010 caiu para $\mathrm{R} \$ 39.684,12$, queda de $27,4 \%$, sendo o setor industrial, que apresentou queda de $18,5 \%$, o maior responsável por esta queda.

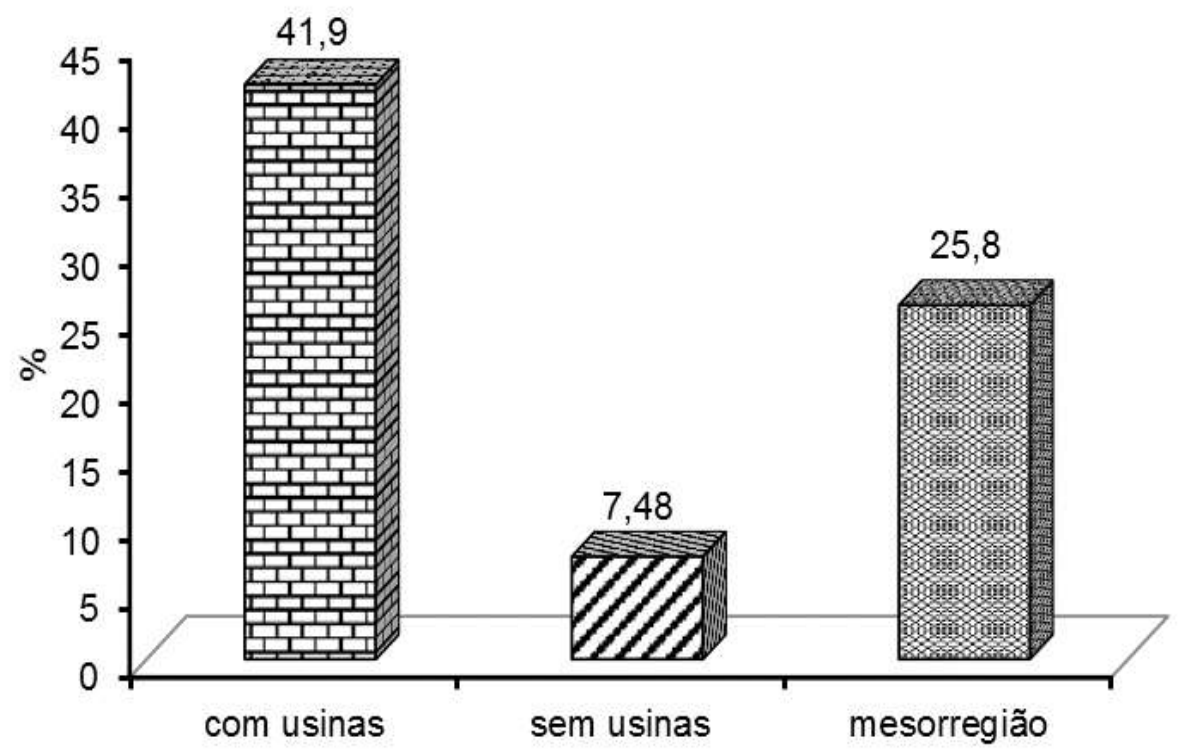

Figura 4. Variação Produto Interno Bruto per capitaa preços reais dos municípios com e sem usinas canavieiras e da mesorregião de Araçatuba 2000-2009.

Fonte: Elaborada pelo autor a partir de dados da FSEADE (2012).

O PIB per capita considerando o total dos municípioscom usinas canavieiras cresceu relativamente em maior proporção (Figura 4) de $\mathrm{R} \$ 280.615,81$ para 398.133,26 (alta de $41,9 \%$ ), do total dos municípios sem usinas o aumento foi bem menor de $7,5 \%$, de $\mathrm{R} \$$

${ }^{2}$ Os preços foram indexados pelo Índice Geral de Preços - Disponibilidade Interna (IGP-DI) publicado pela Fundação Getúlio Vargas, para dezembro 2010.

Cultura Agronômica, Ilha Solteira, v.24, n.2, p.181-196, 2015 
246.068,10 para $\mathrm{R} \$ 264.475,90$, e finalmente em relação à mesorregião de Araçatuba o acréscimo foi de $\mathrm{R} \$ 526.683,90$ para $\mathrm{R} \$$ 662.609,16 (ampliação de 25,8 \%). De alguma forma as usinas devem ter contribuído para elevação do PIB per capita.

A tabela 4 apresenta os Índices da Firjan de Desenvolvimento Municipal (IFDM) com usinas canavieiras nos anos de 2000, 2005 e 2009. Analisando individualmente o município que mais se destacou foi Suzanápolis que passou de 0,56 para 0,84 (aumento de 50,3\%) de 2000 a 2009.

Tabela 4. Índice Firjan de Desenvolvimento dos Municípios com usinas canavieiras na mesorregião de Araçatuba 2000, 2005 e 2010 e suas variações.

\begin{tabular}{l|l|l|l|r|r|r}
\hline \multirow{2}{*}{ Município } & \multicolumn{7}{|c}{ IFDM } \\
\cline { 2 - 7 } & $\mathbf{2 0 0 0}$ & $\mathbf{2 0 0 5}$ & $\mathbf{2 0 0 9}$ & $\begin{array}{r}\text { Var.\% } \\
\mathbf{0 5 / 0 0}\end{array}$ & $\begin{array}{r}\text { Var \% } \\
\mathbf{0 9 / 0 5}\end{array}$ & $\begin{array}{c}\text { Var. \% } \\
\mathbf{0 9 / 0 0}\end{array}$ \\
\hline Andradina & 0,74 & 0,77 & 0,77 & 3,6 & 0,81 & 4,46 \\
\hline Araçatuba & 0,78 & 0,87 & 0,88 & 11,6 & 1,27 & 12,97 \\
\hline Avanhandava & 0,68 & 0,70 & 0,69 & 4,2 & $-2,32$ & 1,83 \\
\hline Bento de Abreu & 0,69 & 0,81 & 0,72 & 17,9 & $-11,78$ & 4,01 \\
\hline Brejo Alegre & 0,68 & 0,69 & 0,84 & 1,7 & 21,54 & 23,65 \\
\hline Buritama & 0,76 & 0,71 & 0,77 & $-5,4$ & 7,54 & 1,74 \\
\hline Castilho & 0,67 & 0,77 & 0,69 & 14,5 & $-10,30$ & 2,72 \\
\hline Clementina & 0,70 & 0,76 & 0,84 & 7,7 & 10,51 & 19,01 \\
\hline Guararapes & 0,70 & 0,79 & 0,79 & 12,9 & $-0,56$ & 12,29 \\
\hline Mirandópolis & 0,72 & 0,74 & 0,70 & 3,6 & $-5,50$ & $-2,13$ \\
\hline N. Independência & 0,65 & 0,69 & 0,59 & 5,8 & $-14,27$ & $-9,33$ \\
\hline Penápolis & 0,72 & 0,81 & 0,75 & 12,2 & $-8,14$ & 3,11 \\
\hline Pereira Barreto & 0,71 & 0,75 & 0,74 & 6,0 & $-1,68$ & 4,23 \\
\hline Santo Antônio do Aracanguá & 0,73 & 0,79 & 0,84 & 7,6 & 6,59 & 14,67 \\
\hline Sud Mennucci & 0,71 & 0,80 & 0,76 & 14,1 & $-5,31$ & 7,99 \\
\hline Suzanápolis & 0,56 & 0,69 & 0,84 & 23,0 & 22,14 & 50,26 \\
\hline Valparaíso & 0,66 & 0,80 & 0,76 & 21,2 & $-5,0$ & 15,64 \\
\hline Média Com usinas & $\mathbf{0 , 7 0}$ & $\mathbf{0 , 7 6}$ & $\mathbf{0 , 7 6}$ & $\mathbf{8 , 6 \%}$ & $\mathbf{0 , 0 \%}$ & $\mathbf{8 , 6 \%}$ \\
\hline Média sem usinas & $\mathbf{0 , 7 1}$ & $\mathbf{0 , 7 3}$ & $\mathbf{0 , 7 4}$ & $\mathbf{2 , 8 \%}$ & $\mathbf{1 , 4 \%}$ & $\mathbf{4 , 2 \%}$ \\
\hline Fonyyyyyyyy
\end{tabular}

Fonte: Elaborada pelo autor a partir de dados do IPEADATA (BRASIL, 2012) e da FIRJAN (2012).

No ano de 2000, com exceção do município de Suzanápolis que apresentava desenvolvimento regular, todos os outros municípios com índice maior que 0,6 estavam classificados como desenvolvimento moderado. Os maiores valores foram obtidos por Araçatuba 0,78, Buritama 0,76 e Andradina 0,74. Neste ano a média do índice Firjan de todos os municípios com usinas 0,70 esem usinas foi de 0,71 .

Em 2005, excluindo Buritama, todos apresentaram aumento no índice Firjan, Sud Mennucci e Valparaiso atingiram 0,8 limite para mudança do estágio de desenvolvimento moderado para alto, Araçatuba novamente apresentou maior valor 0,87, Bento de Abreu e Penápolis 0,81. Comparando o índice de 2000 com o de 2005, Suzanápolis foi que teve

Cultura Agronômica, Ilha Solteira, v.24, n.2, p.181-196, 2015 
maior crescimento 23\%, assim como Valparaiso que aumentou 21,2\%, os dois municípios que em 2000 mostravam os menores valores 0,56 e 0,66 acompanhado de Nova Independência com índice de 0,65. O índice médio aumentou 8,6\% (de 0,70 para 0,76). Em 2009 comparando com 2005 na maioria (09 municípios) o índice caiu, aumentou em 6 municípios e 2 apresentaram o mesmo valor.

Para um período maior de 2000 a 2009, com exceção de Mirandópolis e Nova Independência os outros municípios apresentaram valores positivos. Suzanápolis mostra maior variação no período de 50,26\%, seguido por Brejo Alegre aumento de 23,65\% no índice. Considerando que o IFDM mede o nível de desenvolvimento dos municípios, das dimensões emprego/renda, educação e saúde, em Suzanápolis o fator que predominou neste aumento foi emprego e renda que no período evolui $74 \%$ (de 0,42 para 0,73 ), muito embora os outros fatores também apresentassem crescimento. Por outro lado o município que apresentou maior variação negativa foi Nova Independência de 0,65 para 0,59, queda de $9,3 \%$. Neste caso o que contribuiu para redução do índice foi o não fornecimento de informações sobre o fator renda em 2009 pelo município, segundo dados disponibilizados pela IPEADATA (BRASIL, 2012).

Analisando pela ótica dos municípios com e sem usinas dentro da mesorregião de Araçatuba notamos um crescimento de ambas as médias nos períodos estudados. O maior aumento ocorreu de 2000 a 2009, com os dados médios dos municípios com usinas o índice passou de 0,70 para 0,76 (aumento de 8,6\%), sem usinas a variação foi menor de 0,71 para $0,74(4,2 \%)$.Esses resultados evidenciam uma melhoria no índice Firjan para os municípios com presença de usinas e sem usinas, muito embora em todo o período, não tenha havido mudança de estágio estes municípios continuam classificados como desenvolvimento moderado (variação de 0,6 a 0,8 ).

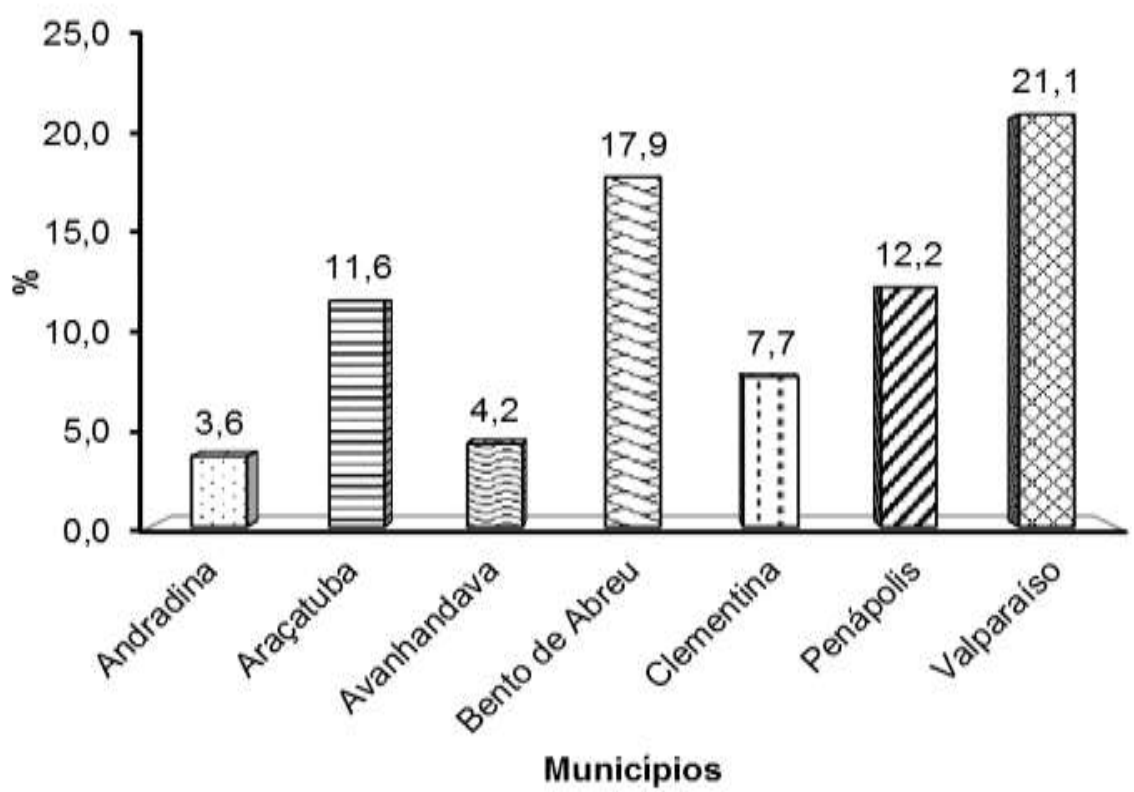

Figura 5. Variação do IFDM dos 07 municípios com usinas canavieiras implantadas no período de 2000 a 2005 na mesorregião de Araçatuba.

Fonte: Elaborada pelo autor a partir de dados do IPEADATA (BRASIL, 2012) e da FIRJAN (2012).

Cultura Agronômica, Ilha Solteira, v.24, n.2, p.181-196, 2015 
É interessante separar em dois períodos a análise do IFDM tendo em vista que das 20 usinas implantadas na mesorregião 7 foram antes de 2005. Com relação ao período de 20002005 os municípios de Valparaíso e Bento de Abreu apresentaram maiores taxas de crescimento de $21,1 \%$ e $17,9 \%$ simultaneamente. Os fatores que determinaram esse aumento para Valparaíso foram emprego e renda (28 \%) e saúde (37 \%). Para Bento de Abreu foi o fator saúde com crescimento de $47 \%$ (Figura 5).

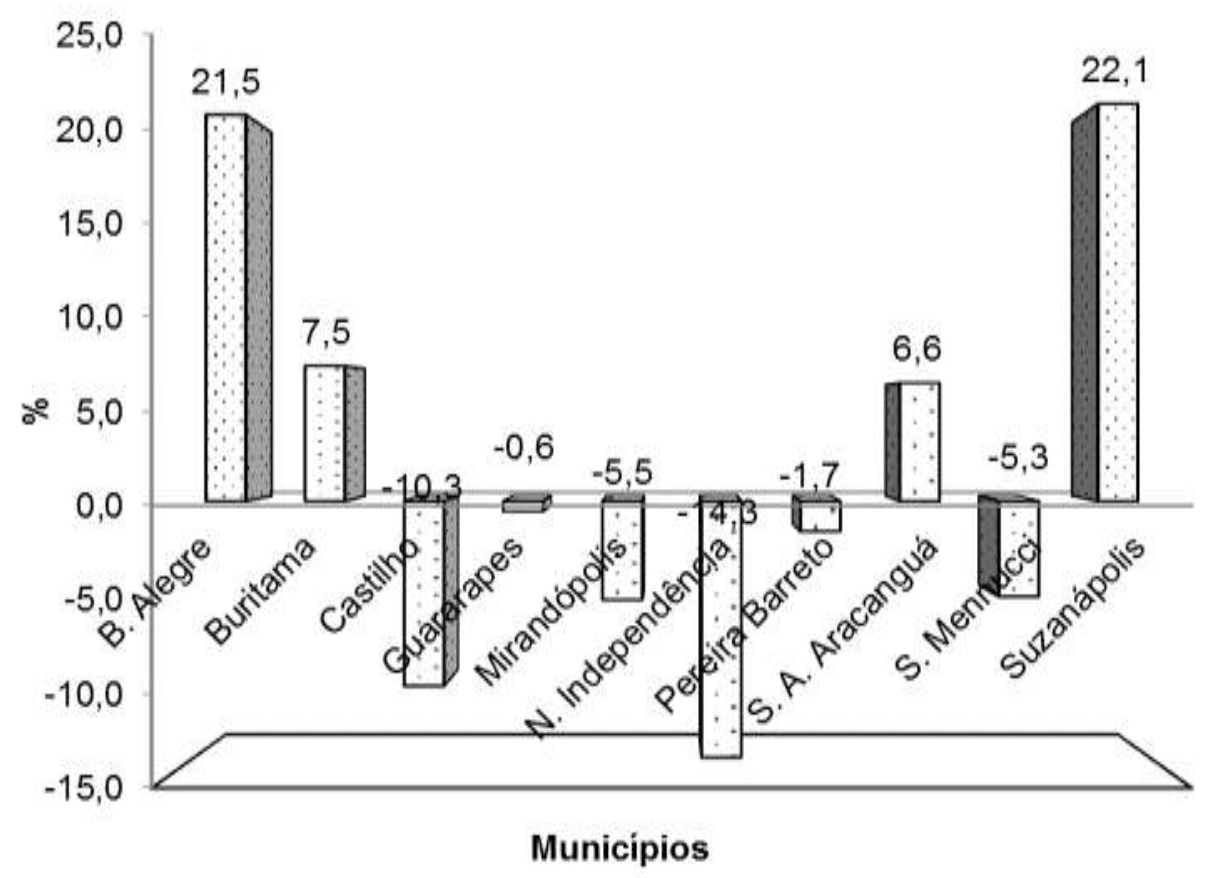

Figura 6. IFDM dos 10 municípios com usinas canavieiras implantadas após 2005 na mesorregião de Araçatuba.

Fonte: Elaborada pelo autor a partir de dados do IPEADATA (BRASIL, 2012) e da FIRJAN (2012).

$\mathrm{Na}$ análise para o período mais recente (2005 a 2009) constata-se apenas 4 municípios com resultados positivos, para os outros 6 foram negativos. Destacam-se os municípios de Suzanápolis com aumento de $22,1 \%$, devido somente ao fator emprego/ renda (73\%) e Brejo Alegre com 21,5\% também devido a emprego/ renda (64 \%) e pela melhoria na saúde (23\%). Nestes municípios em 2008 foram implantadas usinas canavieiras, que devem responder, pelo menos em parte, por estes resultados. Por outro lado, os municípios com resultados negativos, Nova Independência (14,3\%) e Castilho (10,3\%), em ambos os casos o fator emprego/renda é que foi responsável por esta queda. No caso de Nova Independência verificou-se que para estimar o Índice da Firjan em 2009 não foi fornecido o indicador de renda/emprego, justificando a queda de 14,3\% (Figura 6).

Tsukada (2011) verificou que o IDHM melhorou na região de Marília-SP como um todo, e em alguns dos municípios que apresentaram maior evolução do índice estão localizadas usinas. Por outro indicador o IPRS apontou que os municípios com unidades sucroalcooleiras não seguem um padrão econômico ou social, estando presentes em municípios com riqueza entre baixa e alta e extremamente baixa.

Cultura Agronômica, Ilha Solteira, v.24, n.2, p.181-196, 2015 
Palomino et al. (2008) analisando se a presença da cultura canavieira e de usinas afetavam o desempenho da arrecadação fiscal dos municípios paulistas, verificaram uma relação positiva entre arrecadação per capita e presença de usinas e cana-de-açúcar.

Maior dinamismo econômico ocorre devido ao fato das remunerações neste setor serem maiores do que em outras atividades agrícolas. Os modelos estimados confirmaram que o setor canavieiro e a receita fiscal apresentam uma relação positiva nas economias locais. Embora, as remunerações possam ser maiores. Neste trabalho verificou-se maior migração da área rural e um menor número de vínculos empregatícios nos municípios com usinas da mesorregião de Araçatuba, e nos demais setores como comércio, indústria e serviços um avanço significativo.

\section{CONSIDERAÇÕES FINAIS}

As análises dos resultados obtidos nos municípios localizados na mesorregião de Araçatuba indicaram que:

Confrontando o período 2000 a 2010, com a presença de usinas canavieiras, a população urbana cresceu $9,5 \%$, e na área rural houve uma queda $13,1 \%$. Nos municípios sem usinas aumentou a população urbana $(13,1 \%)$ e a população rural $(12,2 \%)$;o número de pessoas ocupadas no setor industrial, no período de 2000 a2010 cresceu em todos os municípios com usinas canavieiras na mesorregião de Araçatuba, exceção feita ao município de Guararapes. No comércio observou-se crescimento em todos os municípios, e no setor agropecuário o resultado foi diferente, 08 municípios apresentaram crescimento, e por fim no setor de serviços apenas o município de Brejo Alegre apresentou redução. No total dos municípios houve queda no setor agropecuário, de quase $5 \%$ com presença de usinas e de 2,5\% sem usinas; o PIB per capita da mesorregião de Araçatuba cresceu 25,8\% de (2000-2009), considerando o total dos municípios com usinas canavieiras o PIB per capita cresceu mais $41,9 \%$, dos municípios sem usinas o aumento foi bem menor 7,5\%. De alguma forma as usinas devem ter contribuído para elevação do PIB per capita nos seus municípios; houve uma melhoria no índice da Firjan de 2000 a 2009 para os municípios com presença de usinas $(0,70$ para 0,76$)$ e sem a presença de usinas $(0,71$ para 0,74$)$.Apesar de em todo o período, não tenha havido mudança de estágio, continuam classificados como desenvolvimento moderado.

\section{REFERÊNCIAS BIBLIOGRÁFICAS}

AGRIANUAL 2014. Anuário da agricultura brasileira. São Paulo: Informa Economics South America/FNP, 2014. 226 p.

BARBOSA, R. D. R.; LUDWIG, M. P.; LORETO, M. D. D. S.; SOUSA, J. M. M. Agroindústria canavieira e desenvolvimento local na percepção de diferentes segmentos sociais, Bambuí (MG). Oikos: Revista Brasileira de Economia Doméstica, Viçosa, v. 22, n.1, p. 230-256, 2011. 
BRASIL - Ministério de Minas e Energia. Mercado internacional de biocombustíveis. In: Análise de conjuntura dos biocombustíveis ano 2013. Brasília: EPE, 2014. Cap. 7 ,

p. 44-46. Disponível em: $<$ http://www.epe.gov.br/Petroleo/Documents/An\%C3\%A1lise\%20de\%20Conjuntura\%20do s\%20Biocombust\%C3\%ADveis\%20\%20boletins\%20peri\%C3\%B3dicos/An\%C3\%A1lise\% 20de\%20Conjuntura\%20-\%20Ano\%202013.pdf>. Acesso em: 04 nov. 2014.

BRASIL - PRESIDÊNCIA DA REPÚBLICA FEDERATIVA DO BRASIL. Instituto Brasileiro de Geografia e Estatística. FIBGE. Brasília: IBGE, Censo Demográfico 2010. Disponível em : <http://www.censo2010.ibge.gov.br/sinopse/index.php?dados=29\&uf=35>. Acesso em: 04 jul. 2012.

BRASIL - MINISTÉRIO DA AGRICULTURA, PECUÁRIA E ABASTECIMENTO. Sistema de Acompanhamento da Produção Canavieira. Cadastro de instituições: relação de instituições cadastradas no Departamento da Cana-de-açúcar e Agroenergia. Brasília: MAPA/CGAE/DCAA 2014. 13 p. Disponível em: <http://www.agricultura.gov.br/arq_editor/file/Desenvolvimento_Sustentavel/Agroenergia/Orient acoes_Tecnicas/Usinas\%20e\%20Destilarias\%20Cadastradas/Relat\%C3\%B3rio\%20de\%20dados $\% 20$ cadastrais\%20de\%20institui\%C3\%A7\%C3\%B5es_20_05_2014.pdf>. Acesso em: 02 jul. 2014.

BRASIL - PRESIDÊNCIA DA REPÚBLICA FEDERATIVA DO BRASIL. Instituto de Pesquisa Econômica Aplicada - Ipeadata. Brasília: IPEA, 2012. Disponível em: <http://www.ipeadata.gov.br/>. Acesso em: 15 ago. 2012.

CAMARGO JUNIOR, A. S; TONETO JUNIOR, R. Indicadores sócio-econômicos e a cana-de-açúcar no Estado de São Paulo. Informações Econômicas, São Paulo, v. 39, n. 6, p.57-67, 2009.

COMPANHIA NACIONAL DE ABASTECIMENTO - CONAB, 2014. Acompanhamento da safra brasileira: cana-de-açúcar - safra 2014/15. Primeiro levantamento - abril de 2014. Disponível em: 〈www.conab.gov.br〉. Acesso em: 4 junho 2014.

FSEADE - FUNDAÇÃO SISTEMA ESTADUAL DE ANÁLISE DE DADOS. Informações dos Municípios Paulistas. São Paulo: FSEADE, 2012. Disponível em: <http://www.seade.gov.br/>. Acesso em: 10 jun. 2014.

MONTAGNHANI, B. A.; FAGUNDES, M. B. B.; SILVA, J. F. O papel da agroindústria canavieira na geração de empregos e no desenvolvimento local: o caso da usina mundial no município de Mirandópolis, Estado de São Paulo. Informações Econômicas, São Paulo, v. 39, n. 12, p.26-38, 2009.

Cultura Agronômica, Ilha Solteira, v.24, n.2, p.181-196, 2015 
PALOMINO, J. M.; TONETO JUNIOR, R.; CAMPOS, C. V. C.; STOCCO, L. Expansão da cana-de-açúcar e o impacto sobre a arrecadação fiscal dos municípios paulistas. In: CONGRESSO DA SOCIEDADE BRASILEIRA DE ECONOMIA, ADMINISTRAÇÃO E SOCIOLOGIA RURAL, 46., 2008, Rio Branco. Anais... Rio Branco: SOBER, 2008. p.121. Disponível em:<http://www.sober.org.br/palestra/9/445.pdf>. Acesso em: 15 jun. 2012.

PROENÇA, E. R. Concentração, integração horizontal e vertical das usinas canavieiras. 2012. 125 f. Tese (Doutorado em Agronomia - Sistemas de Produção) Faculdade de Engenharia, Universidade Estadual Paulista, Ilha Solteira, 2012.

SHIKIDA, P. F. A.; SOUZA, E. C. Agroindústria canavieira e crescimento econômico local. Revista de Economia e Sociologia Rural, Brasília, v. 47, n. 3, p.569-600, 2009. Disponível em: 〈http://www.scielo.br/pdf/resr/v47n3/v47n3a02.pdf>. Acesso em: 25 jun. 2012.

TSUKADA, C. Y. P. S. Os efeitos da expansão do setor sucrolacooleiro sobre odesenvolvimento de municípios da Região Administrativa de Marília/SP. 2011. 180 f. Dissertação (Mestrado em Geografia - Desenvolvimento Regional) - Faculdade de Ciência e Tecnologia, Universidade Estadual Paulista, Presidente Prudente, 2011. 